\title{
Soil erosion prediction based on land cover dynamics at the Semenyih watershed in Malaysia using LTM and USLE models
}

\begin{abstract}
This study attempts to identify and forecast future land cover (LC) by using the Land Transformation Model (LTM), which considers pixel changes in the past and makes predictions using influential spatial features. LTM applies the Artificial Neural Networks algorithm) in conducting the analysis. In line with these objectives, two satellite images (Spot 5 acquired in 2004 and 2010) were classified using the Maximum Likelihood method for the change detection analysis. Consequently, LC maps from 2004 to 2010 with six classes (forest, agriculture, oil palm cultivations, open area, urban, and water bodies) were generated from the test area. A prediction was made on the actual soil erosion and the soil erosion rate using the Universal Soil Loss Equation (USLE) combined with remote sensing and GIS in the Semenyih watershed for 2004 and 2010 and projected to 2016. Actual and potential soil erosion maps from 2004 to 2010 and projected to 2016 were eventually generated. The results of the LC change detections indicated that three major changes were predicted from 2004 to 2016 (a period of 12 years): (1) forest cover and open area significantly decreased at rates of almost 30 and $8 \mathrm{~km}^{2}$, respectively; (2) cultivated land and oil palm have shown an increment in sizes at rates of 25.02 and $5.77 \mathrm{~km}^{2}$, respectively; and, (3) settlement and Urbanization has intensified also by almost $5 \mathrm{~km}^{2}$. Soil erosion risk analysis results also showed that the Semenyih basin exhibited an average annual soil erosion between 143.35 ton $\mathrm{ha}^{-1}$ year $^{-1}$ in 2004 and 151 in 2010, followed by the expected 162.24 ton ha $^{-1}$ year $^{-1}$. These results indicated that Semenyih is prone to water erosion by 2016. The wide range of erosion classes were estimated at a very low level (0-1 t/ha/year) and mainly located on steep lands and forest areas. This study has shown that using both LTM and USLE in combination with remote sensing and GIS is a suitable method for forecasting LC and accurately measuring the amount of soil losses in the future.
\end{abstract}

Keyword: Soil erosion; Geographic information system; Watershed; Land transformation model; Remote sensing; Universal soil loss equation 